\title{
Collection of pancreatic juice in experimental animals: mini-review of materials and methods
}

\author{
R Zabielski ${ }^{1 *}, \mathrm{~V}_{\text {Leśniewska }}{ }^{1}, \mathrm{P}$ Guilloteau ${ }^{2}$ \\ ' Department of Animal Physiology, Faculty of Veterinary Medicine, Warsaw Agricultural \\ University, ul. Nowoursynowska 166, 02-787 Warsaw, Poland; \\ ${ }^{2}$ Laboratoire du jeune ruminant, Inra, 65, rue du St Brieuc, 35042 Rennes cedex, France
}

(Received 2 January 1996; accepted 10 April 1997)

\begin{abstract}
Summary - This article briefly describes some anatomical details of the pancreatic duct system in dogs, cats, cattle, sheep, goats, pigs and rats that are important for the preparation of pancreatic ducts for surgery. The advantages and disadvantages of various materials used for preparing cannulas and catheters for the collection of pancreatic juice are also presented. Several techniques of pancreatic duct cannulation (Thomas', duodenal pouch and Routley's methods) and pancreatic juice collection are discussed with regards to the specificity of different animal species. The results of various collections of pancreatic juice obtained in different laboratories, and resulting from the application of specific methods for particular experimental purposes are discussed.
\end{abstract}

surgical model / pancreatic juice collection / chronic study / dog / pig / cattle / sheep / rat

Résumé - Collecte du suc pancréatique chez des animaux en expérimentation : matériels et méthodes utilisés. Cette revue décrit brièvement quelques particularités anatomiques du canal pancréatique chez le chien, le chat, les bovins, les ovins, les caprins, le porc et le rat. Elles doivent être prises en compte lors de la pose d'un cathéter du canal pancréatique. Les avantages et inconvénients de divers matériaux utilisés pour la préparation des canules et des cathéters sont également présentés. Plusieurs techniques de cathétérisation du canal pancréatique (méthodes de Thomas ou de Routley, préparation de poche duodénale) et de collecte du suc pancréatique sont discutées suivant les particularités des différentes espèces. Les divergences des résultats obtenus lors de l'utilisation de différentes méthodes (adaptées aux objectifs fixés) sont discutées.

modèle chirurgical / collecte de suc pancréatique / étude chronique / chien / porc / bovin / ovin / rat

\footnotetext{
* Correspondence and reprints

Tel/fax: + (48) 22472 452; e-mail: zabielski@alpha.sggw.waw.pl
} 


\section{INTRODUCTION}

Experimental approaches to investigate the exocrine pancreas function involve both in vivo and in vitro methods. Methods in vivo involve chronic and acute preparation of a pancreatic fistula in experimented animals. Methods in vitro include secretion studies on the isolated perfused pancreas, lobuli, acini or single acinar cells as well as on tissue preparations on a subcellular level. There is currently no universal method, and the specific goal of this study is to define a basic criterion for selecting the most convenient approach. Methods consisting of chronic preparation of pancreatic fistula are the preferred methods to study some of neuro-hormonal relations as well as the nutritional and behavioural aspects. Isolated preparations of the pancreas, lobuli and acini are used to identify more specific effects of a single factor, while cellular or subcellular preparations provide a more in-depth approach to investigate the stimulus-secretion coupling on a molecular level. However, here again whole-animal studies are necessary to verify the physiological relevance of the results obtained in vitro. As an example, despite the abundance of cholecystokinin (CCK) membrane receptors in the pancreas demonstrated in vitro (Le Meuth et al 1993), recent in vivo studies suggest that their physiological importance is overestimated and that the physiological mechanism of CCK action on pancreatic secretion is located in the duodenum (Owyang, 1996; Guilloteau et al, 1997). Considerable progress has been made in the methodology of preparing chronic animal models for exocrine pancreas study. It concerns major advances in the topography of the pancreatic duct system, materials for implantation, surgical techniques as well as methods of collection of pancreatic juice. Some of these aspects are further discussed below.

\section{PANCREATIC DUCT SYSTEMS IN ANIMAL SPECIES}

The pancreas is a relatively fixed organ (with short mesentery) located deep between the duodenum and liver in the right upper part of the abdomen. The whole gland is delicate, richly innervated and vascularized, hence a surgical approach is troublesome. Rough, inpatient cannulation may disturb local blood flow and innervation, damage the pancreatic tissue, and thus produce artifactual results. The exocrine pancreas is composed of pancreatic acini and a branched excretory duct system. Pancreatic acinar cells synthesize, store and release pancreatic enzymes and enzyme precursors into the ducts, and the ductal cells secrete water and electrolytes. The pancreatic excretory duct is a tree-like system; the smallest ducts contact pancreatic acini and combine in intralobular and then perilobular ducts meeting to form a pancreatic duct or ducts that carry the juice out into the duodenum. There are considerable differences between species concerning the topography of the pancreatic duct system. This is caused by the fact that the pancreas develops from the embryonic duodenum by two budlike primordia: dorsal and ventral. Each primordium communicates individually with the duodenum. The duct of the ventral primordium is the pancreatic duct (formerly referred to as the Wirsung's duct) and opens together with the bile duct on the major duodenal papilla. The duct of the dorsal primodium is the accessory pancreatic duct (formerly referred to as the Santorini's duct) and opens on the minor duodenal papilla (Nickel et al, 1979). In the later stages of fetal development, the two pancreatic primordia fuse into one organ, and the duct system evolves in a species specific manner (fig 1).

\section{Dog}

In the dog, the two pancreatic ducts remain separated (Grahame, 1943; Nickel et al, 
Dog

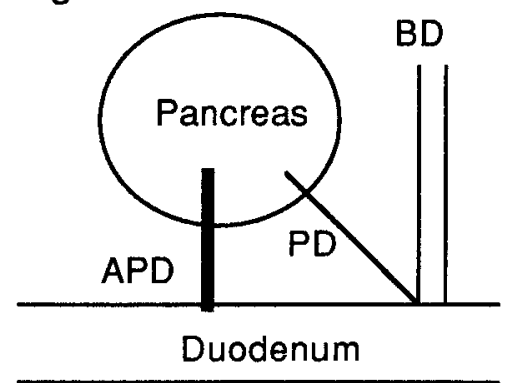

Cat

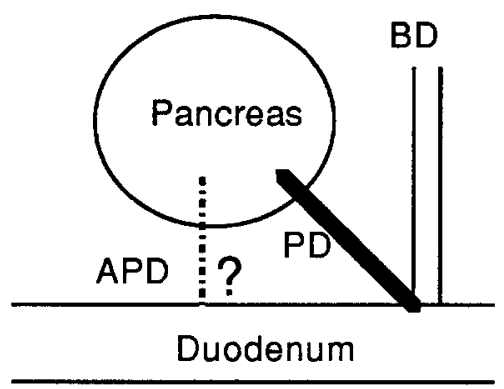

Pig \& Cattle

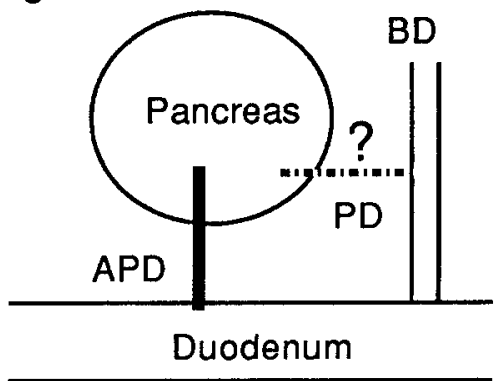

Rat \& Small Ruminants

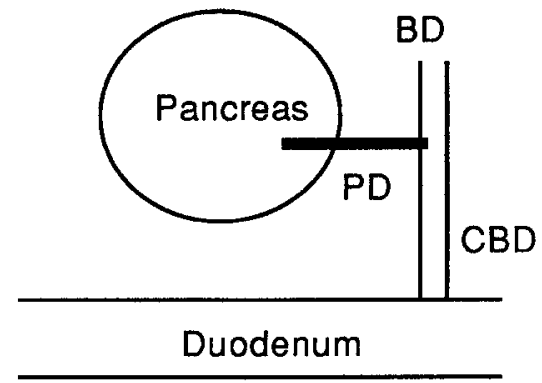

APD: accessory pancreatic duct; PD: pancreatic duct; BD: bile duct; CBD: common bile duct; ?: duct present only in certain animals.

Fig 1. Schematic presentation of the pancreatic duct system in dogs, pigs, cattle, cats, rat and small ruminants.

1979). The pancreatic (Wirsung's) duct that meets the duodenum, together with the bile duct (fig 1) on the major duodenal papilla, is small and secretes a very small amount of pancreatic juice. This duct is ligated in most surgical techniques. A few millimeter fragment of the pancreatic duct and its orifice can be seen on the lesser curvature of the duodenum, sometimes even without the preparation of the right pancreatic lobe. The accessory pancreatic duct, in fact, is considerably larger than the aforementioned pancreatic duct, and it has its own opening into the duodenum on the minor duodenal papilla. To access Santorini's duct for cannulation, a little preparation between the pancreas and the duodenum a few centimeters distal to the major duodenal papilla is necessary.

\section{Pig}

In the pig, usually only the accessory pancreatic duct is observed (Pierzynowski et al, 1988b; Winnicki, 1994). Vodovar et al (1964), however, have also reported the presence of the pancreatic duct in $18 \%$ of the pigs studied (fig 1). Differences in breed may account for these discrepancies. In all reported techniques only the accessory pan- 
creatic duct is accessed. Initially, localization of the accessory pancreatic duct may prove difficult because this duct is buried deeply in the pancreatic tissue and is neither visible nor palpable. The accessory pancreatic duct is exposed for catheterization after gentle preparation of the terminal part $(1-1.5 \mathrm{~cm})$ of the right pancreatic lobe from the lesser curve of the duodenum.

\section{Cattle}

In cattle, both the accessory pancreatic duct and the pancreatic duct(s) may exist (Wass, 1965). However, a considerably larger portion of the pancreatic juice drains through the accessory pancreatic duct. This duct enters the duodenum separately on the minor duodenal papilla, which is located 20 to $40 \mathrm{~cm}$ distal to the major duodenal papilla (fig 1 ). In most of cannulated cows and calves (Friesian, Siementaler and Jersey), the accessory pancreatic duct was hidden between pancreatic lobuli, but its duodenal orifice was palpable in the distal part of the right lobe. Rentgenological studies have revealed that a significant percentage of cattle possesses the pancreatic duct(s), which open(s) into the bile duct (Wass, 1965). This or these small connections are usually not ligated during surgery owing to a difficult surgical approach. St-Jean et al (1992) ligated the tissues between the pancreas and a common bile duct. There was however no difference in pancreatic secretion with or without the ligation. From their description, it appears that all the tissues between the edge of the pancreas and the common bile duct were ligated without first checking if such connections were present. We observed pancreatic juice contamined with bile in about $5 \%$ of Friesian calves with cannulated accessory pancreatic ducts.

\section{Cat}

In the cat, the pancreatic (Wirsung's) duct exists (Konturek et al, 1970; Nickel et al,
1979). This duct is located in the right pancreatic lobe and enters the duodenum on the major duodenal papilla. An accessory pancreatic duct may also exist in exceptional cases (fig 1).

\section{Rat and small ruminants}

In the rat and small ruminants (sheep and goat), pancreatic duct(s) join(s) the bile duct to form the common bile duct (fig 1) (Nickel et al, 1979; Waynforth, 1980). In the rat, usually more than one pancreatic duct is present while in sheep and goats, a single thin-walled pancreatic duct is located deep between the lobuli. Cannulation of the pancreatic duct in these species is difficult or even impossible. On the other hand, the bile duct and the common bile duct are easy to localize and prepare. Therefore in these species, cannulation of the common bile duct instead of the pancreatic duct is performed. Such a procedure however requires the ligation of the bile duct just above the pancreatic duct orifice and a way of bypassing the bile into the duodenum.

\section{MATERIALS FOR IMPLANTATION}

The type of material used for catheters or cannulas depends largely on the selected surgical method of catheterization. For the collection of pancreatic juice through a catheter inserted into the pancreatic duct via duodenal cannula (fig 2) a wide Thomastype (Thomas, 1941) stainless steel cannula is recommended. A stainless steel cannula is well tolerated by the tissues and resistant to digestive juices and biting. These cannulas may function properly for several years in dogs. Some researchers have used Thomastype cannulas made of polyvinyl chloride (PVC) or polymethacrylate methyl (PMM) (Perspex, Plexiglas, Metaplex) but these materials seem to be less durable than steel, an important aspect especially in dogs. 

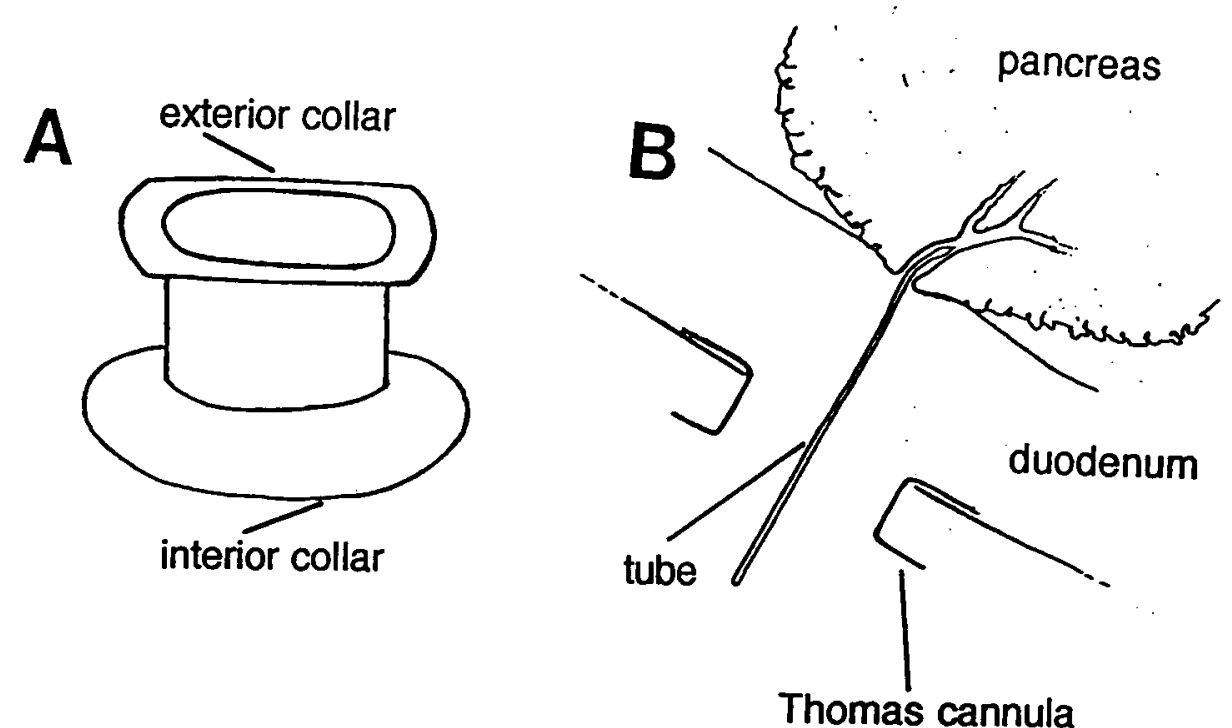

A: Thomas cannula; B: technique for the catheterization of the duct: the top of the catheter is gently bent for easier insertion into the pancreatic duct.

Fig 2. Catheterization of the accessory pancreatic duct via a Thomas cannula in the dog.

Magee and Naruse (1983) successfully used Thomas-type cannulas made of aluminum. Thomas (1941) used short glass tubes inserted through the duodenal cannula into the accessory pancreatic duct. Today, a polyethylene (PE) or PVC tubing is used rather than glass; eg, Magee and Naruse (1983) used the top (last $8-10 \mathrm{~cm}$ ) of a cardiovascular catheter. Catheters made of PE and PVC are elastic, neutral to the tissues and not fragile.

Several types of tubing (PE, PVC, silicone) are commercially available in a wide range of sizes, which are suitable for preparing catheters for chronic implantation. Teflon tubings (politetrafluoroethylene, PTFE) are not recommended because they have little elasticity and bend easily, although this material is well tolerated by tissues. Silicone and PE are most commonly used. Silicone tubings are very elastic, resistant and very well tolerated by the tissues. This mate- rial is available as tubings, plates, powder and glue, and working with the silicone (cutting, glueing and shaping the cannulas) is easy. Thin-walled silicone tubings, however, bend easily (eg, close to the rib or between the abdominal muscles) and may block the flow of juice, the inner and outer diameter should therefore be selected properly. Many researchers have obtained good results with medical grade silicone materials, tubings Silastic and glue - Medical Adhesive Silicone Type A from Dow-Corning Corp (Midland, USA). PE is a little cheaper than silicone, but presents some of the same faults as teflon. PE is stiff, which may block pancreatic duct flow just in front of the catheter tip inserted into the duct, but it is easier to insert into the duct than the silicone catheter. PE is therefore advisable for acute rather than chronic studies. Tubings made from elastic PVC were less tolerated compared to silicone or $\mathrm{PE}$, although in recent years the tech- 
Table I. Comparison of the three methods most frequently used for collection of pancreatic juice in experimental animals.

\begin{tabular}{|c|c|c|c|}
\hline & Thomas' method & Duodenal pouch method & Routley direct method \\
\hline \multicolumn{4}{|l|}{ Method } \\
\hline References & $\begin{array}{l}\text { Thomas, 1941; } \\
\text { Scott et al, 1941; } \\
\text { Hill and Taylor, } 1957\end{array}$ & $\begin{array}{l}\text { Dragstedt et al, 1930; } \\
\text { Preshaw and Grossman, 1965; } \\
\text { Herrera et al, } 1968\end{array}$ & $\begin{array}{l}\text { Routley et al, 1952; Butler } \\
\text { et al, 1960; Corring et al, } 1972\end{array}$ \\
\hline Principle & $\begin{array}{l}\text { Temporal intubation of } \\
\text { pancreatic duct via a wide } \\
\text { duodenal cannula }\end{array}$ & $\begin{array}{l}\text { Preparation of duodenal } \\
\text { pouch containing pancreatic } \\
\text { duct orifice }\end{array}$ & $\begin{array}{l}\text { Chronic implantation of a } \\
\text { catheter in the pancreatic duct }\end{array}$ \\
\hline Reintroduction of juice & $\begin{array}{l}\text { By natural way, after } \\
\text { removing the collection } \\
\text { tubing }\end{array}$ & $\begin{array}{l}\text { By various means of } \\
\text { duodenal cannulas }\end{array}$ & $\begin{array}{l}\text { By duodenal cannula, needs } \\
\text { support }\end{array}$ \\
\hline \multicolumn{4}{|l|}{ Surgery } \\
\hline Surgical procedure & $\begin{array}{l}\text { Simple, continuity of the } \\
\text { tissues minimally affected }\end{array}$ & $\begin{array}{l}\text { Extended preparation of } \\
\text { tissues, interruption of } \\
\text { duodenal continuity }\end{array}$ & $\begin{array}{l}\text { Simple, precise preparation of } \\
\text { pancreatic duct, continuity of } \\
\text { tissues minimally affected }\end{array}$ \\
\hline Postsurgical recovery & Smooth ( $0 \%$ mortality) & High mortality ( $25-85 \%$ ) & Smooth (mortality <3\%) \\
\hline Handling of operated animals & No special requirements & Frequent cleaning cannulas & Frequent controlling juice flow \\
\hline \multicolumn{4}{|l|}{ Animals } \\
\hline$\overline{\text { Species }}$ & Dog, sheep & Dog, pig, cattle & Rat, dog, cat, pig, cattle, sheep \\
\hline Age & $\begin{array}{l}\text { Adult, not recommended for } \\
\text { fast growing and fat animals }\end{array}$ & Growing and adult & Any age including newborns \\
\hline \multicolumn{4}{|l|}{ Collection of pancreatic juice } \\
\hline Start after surgery & 4 weeks & Few days & $\begin{array}{l}\text { Immediately after catheter } \\
\text { implantation }\end{array}$ \\
\hline Preparation for collection & Catheterization of the papilla & None & None \\
\hline Animal immobilization & Severe (Pavlov stand) & Minimal or unnecessary & $\begin{array}{l}\text { Minimal or none (animal's } \\
\text { own cage) }\end{array}$ \\
\hline Juice purity & Pure, non-activated & $\begin{array}{l}\text { Contains duodenal juice } \\
(\sim 10 \%) \text {, controversial for } \\
\text { precise enzymological studies }\end{array}$ & Pure, non-activated \\
\hline Functioning of animal & Many years & Several weeks & Several weeks \\
\hline $\begin{array}{l}\text { Complications that may } \\
\text { exclude animal from studies }\end{array}$ & $\begin{array}{l}\text { Rare, damage of the papilla } \\
\text { after unpatient cannulations }\end{array}$ & Frequent (see text) & $\begin{array}{l}\text { Blockage and rejection of } \\
\text { the catheter }\end{array}$ \\
\hline \multicolumn{4}{|c|}{ Applications for a particular study } \\
\hline $\begin{array}{l}\text { Interdigestive secretion / } \\
\text { neurohormonal regulation }\end{array}$ & Recommended & $\begin{array}{l}\text { Not recommended due to } \\
\text { extended tissue preparation } \\
\text { during surgery }\end{array}$ & Recommended \\
\hline Feeding studies & Not recommended & Possible & Recommended \\
\hline Gastrointestinal perfusions & Not recommended & Possible & Recommended \\
\hline Long collections (eg, $24 \mathrm{~h}$ ) & Impossible & Possible & Possible \\
\hline
\end{tabular}


nology for PVC production for medical purposes has greatly improved.

\section{SURGICAL TECHNIQUES AND METHODS OF PANCREATIC JUICE COLLECTION}

In general, methods of pancreatic juice collection are based either on the exposure of duodenal papilla for temporary catheterization or on a chronic modification of the pancreatic duct outlet. A brief comparison of these methods is shown in table I.

\section{Exposure of duodenal papilla}

The method proposed by Thomas (Thomas, 1941; Thomas and Crider, 1946) and modified by Scott et al (1941) was a major milestone in the research methodology on exocrine pancreas function. It was and is still often used, mostly for studies on dogs. Surgical approaches in this species consist of a ligation of the pancreatic (Wirsung's) duct, followed by the implantation of a wide Thomas cannula on the greater curve of the duodenum just in front of the minor duodenal papilla (fig 2). Dogs are used for collection of pancreatic juice after a 4-week minimum recovery period for the pancreas to adapt to the ligation of the pancreatic duct and for proper healing around the cannula. Before the experiment, the cannula is opened, and a glass (or plastic) tube is inserted into the duct (fig 2) and fixed to the external collar of the cannula. As the Thomas cannula is left open during the entire collection, this method is not recommended for feeding experiments. Some authors closed the cannula with special corks for feeding experiments; however, owing to increased duodenal motor activity and digesta flow after a meal, it was very dificult to maintain the tubing inside the duct. After the experiment, the tubing is removed from the duct, the Thomas cannula is closed with the cork, and the pancreatic juice enters the duodenum naturally. This is the main advantage of the Thomas method, since the smooth reintroduction of normal pancreatic juice flow between experiments causes many difficulties with the other methods. Another advantage is that the juice collected is not contaminated with bile, duodenal and gastric secretions and is non-activated by enterokinase. The implantation of Thomas cannula is simple, intestinal continuity and innervation are maintained, and postsurgical complications are very rare. On the other hand, catheterization of the pancreatic duct before the experiment needs some experience. The structure of the duodenal papilla is very delicate, and once the papilla is damaged it may seriously hinder subsequent catheterizations. Several months after surgery, the papilla may move from the centre of the Thomas cannula disabling catheterization of the duct entirely (usually when the cannula has been implanted in too young a dog). The animal must be immobilized in a stand for juice collection, therefore previous training of the animal is necessary; however, once trained, a dog may be used successfully for many years. This method is not recommended for young fast growing, and restless or mobile animals (eg, piglets, beagle dogs). Hill and Taylor (1957), and later Magee (1961), modified this method for collection of pancreatic juice in sheep. In this species, the Thomas cannula was implanted in the duodenum in front of the common bile duct orifice. The bile duct was ligated just above the pancreatic duct orifice and anastomosis between the gallbladder and duodenum (Hill and Taylor, 1957) or jejunum (Magee, 1961) was performed in order to reintoduce bile.

\section{Modification of pancreatic duct orifice}

Pavlov initiated methods for modifying the pancreatic duct orifice (Markowitz, 1954). His method became classic at the beginning 
of this century, although it had some serious disadvantages. Namely, the pancreatic juice was not reintroduced into the gastrointestinal tract, thus the dogs lost water, electrolytes and enzymes and died within a few weeks. Proteolytic enzymes were activated by contact with the duodenal mucosa and caused tryptic ulceration of the skin around the transplanted fragment. Dogs tended to lick the secretion and induced ascending duct infection. Pavlov's idea of preparing a chronic pancreatic fistula has been subsequently improved by many investigators. The most essential approaches were proposed by Dragstedt et al (1930) and Routley et al (1952).

\section{Methods using the formation of a duodenal pouch}

Dragstedt et al (1930) described a new type of pancreatic fistula preparation in the dog. Their method consisted in preparing a large pouch from the upper duodenum, the pylorus was joined to the upper duodenum and the common bile duct was transplanted into either the stomach or upper jejunum. Secretions from the pouch were evacuated by a cannula. In following modifications, the size of duodenal pouch was markedly reduced, thus leaving the region of the pylorus, proximal duodenum and the orifice of the bile duct untouched. The modification by Preshaw and Grossman (1965) became the standard method for decades for studies in dogs and other species. In the dog, according of Pershaw and Grossman, a few milliliter-large duodenal pouch containing the orifice of the accessory pancreatic duct was formed. The duodenal pouch was connected with the duodenum by means of a small metal cannula. Another wide metal cannula was implanted into the duodenum vis-à-vis the outlet of the smaller cannula. After surgery the wide cannula was kept closed, and was opened only for collection of pancreatic juice. Although the surgical
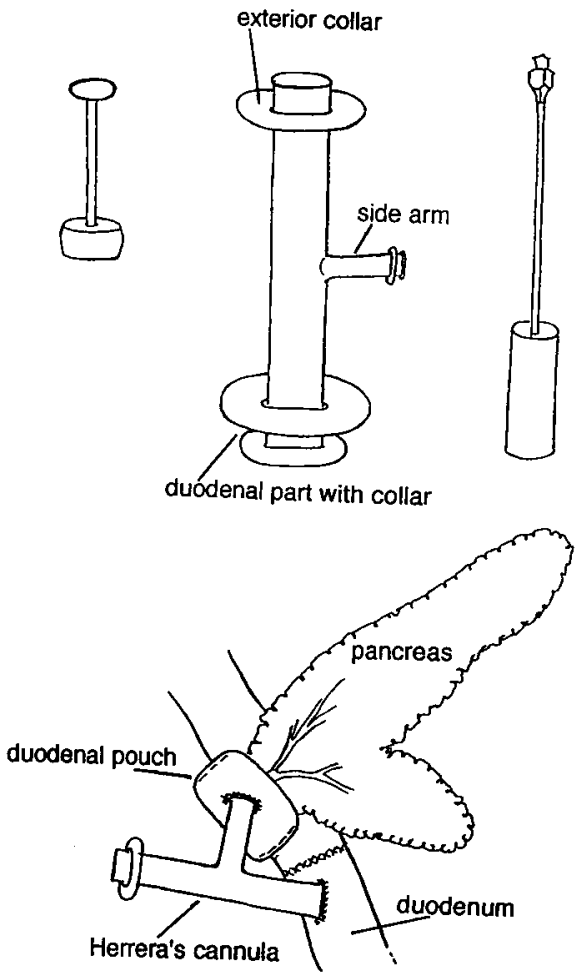

Top: A stainless steel cannula constructed by Herrera with plugs: left plug for closing cannula between the experiments, right plug used during pancreatic juice collection to prevent digesta outflow from the duodenum. Bottom: duodenal pouch with implanted Herrera's cannula.

Fig 3. Herrera's method.

procedure was more complex than that proposed by Thomas, the collection of juice was simple: after opening the wide cannula, one end of a metal tubing was inserted into a cannula draining the pouch and the other end was connected to collecting bags. In later modifications of this method, the two separate cannulas were replaced with a single T-shape metal cannula (fig 3) by Herrera et al (1968). After minor adaptations, this method was applied for pancreatic juice collection in cattle (Ternouth and Buttle, 
1973; St-Jean et al, 1992) and pigs (Źebrowska et al, 1983; Hee et al, 1985; Gabert et al, 1996). Aliev (1974) proposed the implantation of a plastic re-entrant cannula instead of a Herrera-type cannula in pigs.

Many complications arising from preparation of the duodenal pouch have been reported. The extensive surgical procedure caused high postoperative mortality, ie, 25 to $85 \%$ in operated dogs (Teyssen and Niebergall-Roth, 1996). After a certain time, the majority of operated animals developed avascular necrosis of the duodenal pouch, ulceration through the wall of the pouch, leakage from the pouch and duodenum, formation of a functional fistula between the pouch and duodenum, and precipitation of calcium salts inside the cannula (Herrera et al, 1968; Stening, 1969; Ternouth and Butthe, 1973). For these reasons, Stening (1969) and St-Jean et al (1992) introduced several modifications to the cannula construction and surgical procedure.

The pancreatic juice collected by means of pouch methods was not pure: it contained about $10 \%$ duodenal juice and the enterokinase produced by the duodenal pouch activated trypsinogen to trypsin in the pancreatic juice. Moreover the continuity of the duodenum was disrupted thus considerably affecting the duodenal motility and duodeno-pancreatic neural reflexes. Despite these drawbacks, pouch methods are often used in several animal species. The maintenance of the cannulas is simple. Flushing the cannulas with saline once or twice a week seems to prevent the blockage and subseqent complications. Animals could be kept only minimally restrained in their cages during the entire collection (it is especially important in chronic studies on pigs). Besides this important ethical aspect, in animals prepared with duodenal pouches, it was possible to perform feeding studies and, with Herrera-type cannula, intraduodenal perfusions as well. The duodenal pouch methods are recommended by some authors for longlasting experiments, eg, $24 \mathrm{~h}$ (Teyssen and Niebergall-Roth, 1996).

\section{Chronic implantation of the catheter into the pancreatic duct}

The technique proposed by Routley et al (1952) was based on the chronic implantation of an elastic catheter into the pancreatic duct. This method was used for studies in dogs (Routley et al, 1952) and after modifications in cows (Butler et al, 1960; Pierzynowski et al, 1988a), calves (McCormick and Steward, 1966; Zabielski et al, 1992), sheep (Pierzynowski 1983; Kato et al, 1984), goats (Naranjo et al, 1986) piglets (Corring et al, 1972; Pierzynowski et al, 1988b), pigs (Winnicki, 1994), cats (Konturek et al, 1970) and rats (Waynforth, 1980; Green and Miyasaka, 1983; Onaga et al, 1993; Ormai et al, 1986).

In the dog, according to Routley et al (1952), after ligation of the pancreatic duct, the accessory pancreatic duct is cannulated with a polyvinyl resin plastic tubing bypassing the pancreatic duct sphincters. To this purpose, the duct was separated from the adjacent tissues near its duodenal orifice and incised. The catheter was inserted into the duct and attached by means of ligatures (fig 4). The free end of the catheter was exteritorized through the right flank of the abdomen. A similarly constructed catheter was implanted into the stomach and its free end was exteritorized. The two free ends of the catheters were joined in a shunt after surgery to allow for the reintroduction of juice into the GI tract. For collection, the loop was disconnected and the gastric catheter was plugged. This method was successively improved. Butler et al (1960) implanted a polyethylene catheter for reintroduction of the juice into the duodenum instead of the stomach to avoid degradation of pancreatic enzymes. They also protected the pancreatic catheter with a polyethylene 


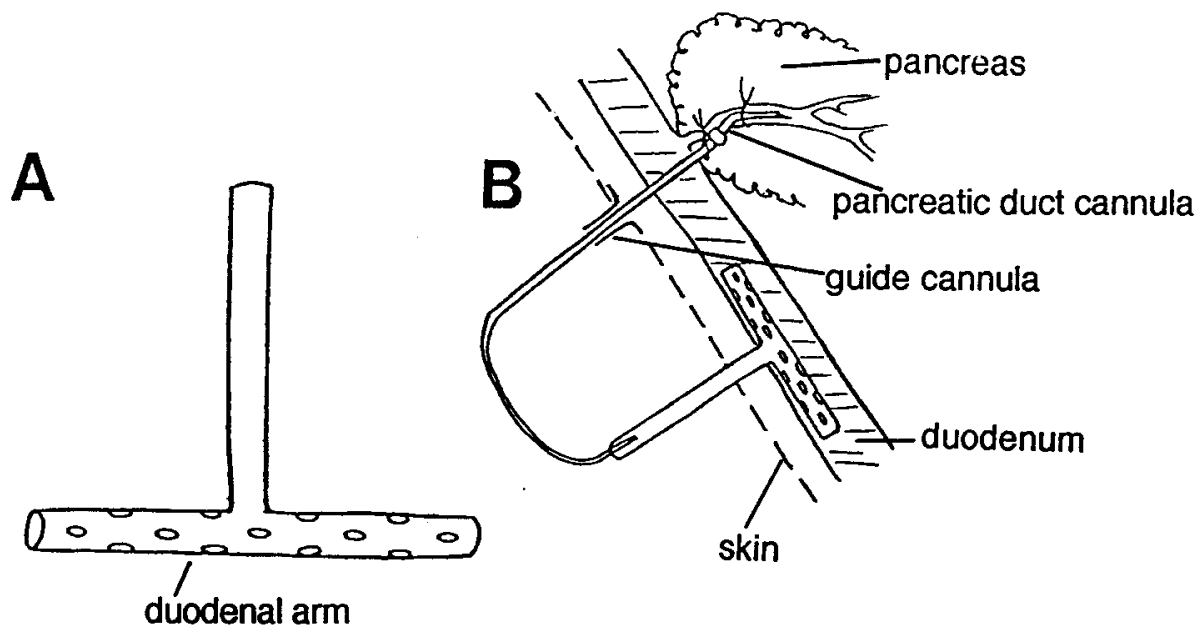

A: perforated T-shape duodenal cannula for smooth reintroduction of pancreatic juice; B: implantation of pancreatic duct cannula. A guide cannula was used to protect the thin silicone tubings implanted in newborn piglets. In older piglets and in calves this guide cannula was not used.

Fig 4. Modification of Routley's method according to Pierzynowski et al (1988) for pancreatic juice collection in young pigs.

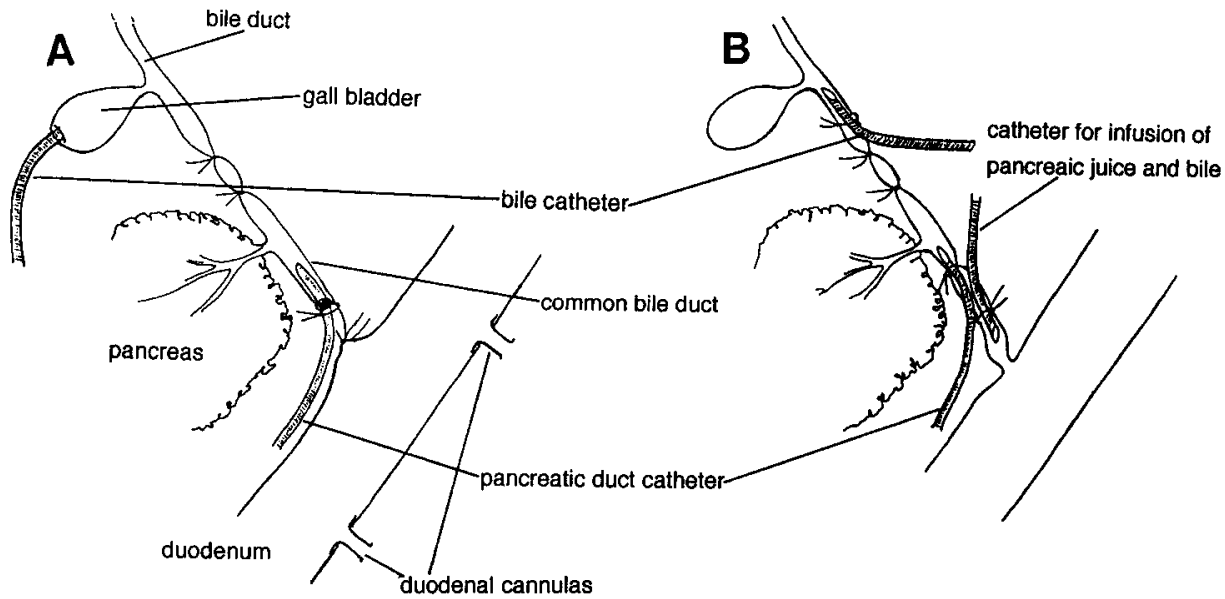

A: Pierzynowski (1983) ligated the bile duct and inserted the catheter into the gall bladder for bile collection. The other catheter was inserted into the common bile duct for pancreatic juice collection. Pancreatic juice and bile were reintroduced by two separate cannulas into the duodenum and jejunum respectively; B: Naranjo et al (1986) ligated the bile duct and then implanted three catheters: one into the bile duct for collection of bile, and two into the common bile duct for collection of pancreatic juice and for reintroduction of juice and bile.

Fig 5. Example techniques of bile ducts cannulation for bile and pancreatic juice collection in sheep (A) and goats (B). 
guide cannula. In further studies, where silicone tubing was used instead of polyethylene, a guide cannula was not used. However, Pierzynowski et al (1988b) used one in newborn piglets (fig 4). Routley's method has also been adopted in sheep (Pierzynowski, 1983; Kato et al, 1984) and goats (Naranjo et al, 1986) (fig 5) as well as in rats (Green and Miyasaka, 1983; Ormai et al, 1986; Onaga et al, 1993).

Collection of pancreatic juice using Routley's method presents several advantages in comparison with pouch techniques. These benefits include the reduction of surgical trauma and the fact that the gut tissue remains virtually intact, thereby retaining intestinal innervation and motility. As a result the animals are able to eat soon after recovery from the anesthesia. Routley's method can therefore be applied to young animals, since neonates cannot tolerate the long period of postoperative starvation required by the pouch technique (Pierzynowski et al, 1990). Moreover, this method permits collection of pure, non-activated pancreatic juice, similar to the Thomas method, but in contrast to the latter the collections can start soon after the surgery. Restraint in Pavlov cage for collection is unnecessary and the entire study could be undertaken on a freely moving animal in its own cage (McCormick and Steward, 1966; Pierzynowski et al, 1988a; Zabielski et al, 1993).

Routley's catheters function for 2 to 3 months if they are cared for properly. This is much shorter compared to Thomas cannulae. We know from Pavlov's studies that, in catheterized animal, the collected pancreatic juice must be reintroduced into the duodenum, and this is the major problem with Routley's catheters. The most frequent cause of catheter failure is a reflux of a duodenal content into the pancreatic catheter and pancreatic ducts leading to a blockage of juice flow. This is due to the bypass of the pancreatic duct sphincter. In our trials, substitution of natural sphincters for one-way valves was ineffective (Zabielski, unpublished). Better results were obtained with permanent collection of pancreatic juice in a retention container and continuous reintroduction of the juice by means of a peristaltic pump in sheep (Kato et al, 1984) and rats (Onaga et al, 1993). In this method, the animal was kept in a metabolic cage, and a persistaltic pump pumped the juice back into the animal at a low constant speed. Adequate pumping rate is difficult to assess, since pancreatic secretion shows marked circadian oscillations (Magee and Naruse, 1983; Onaga et al, 1993; Zabielski et al, 1993). Therefore the dead space of the tubings and the retention container is large, ie, about 5 to $20 \%$ of daily secretion. This fact raises the question of the activity of pancreatic enzymes infused back to the animal. Attempts have also been made to employ more complicated servomechanisms to adjust the rate of juice infusion to the rate of juice secretion (for details, see next section). Another option to solve the problems of reintroduction of the pancreatic juice consisted in a silicone $\mathrm{T}$-shape perforated duodenal cannula (fig 3) introduced by Pierzynowski et al (1988b). The long perforated arm of the cannula implanted in the duodenal lumen almost completely prevents the increase of pressure in the arm connected to the pancreatic catheter. Perforated T-cannulas were successfuly used in piglets and calves of different ages (Pierzynowski et al, 1988b; Zabielski et al, 1992, 1993). They were also used to reintroduce bile in sheep; however, reintroduction of pancreatic juice by means of a perforated T-cannula in rats and sheep failed, probably because of the low rate of juice secretion and its high viscosity (Zabielski, data unpublished).

\section{COLLECTION OF PANCREATIC JUICE}

Usually the pancreatic juice is collected into a small vial (attached to the animal's flank 
or nearby) held in ice and vials are changed manually. Either the volume or weight of the collected juice is measured and after sampling a small portion for the analysis (bicarbonate, total protein, activity of pancreatic enzymes), the remainder is infused back into the animal. In rats, owing to low secretions, the juice is collected in thin tubings held on ice. The reintroduction of pancreatic juice at the rate of secretion is important. Besides its well recognized enzymatic and homeostatic activity, pancreatic juice seems to be an important regulator of intestinal microflora (Pierzynowski et al, 1992). Moreover, a feedback regulation of pancreatic juice was observed in most of examined species (Magee, 1991).

Fraction collectors are often used to reduce manual work; this, however, may increase the dead space of the collection tubings. For precise and high resolution measurements of juice secretion dynamics, a variety of flowmeters have been built. These tools work on a short-circuit (Naruse et al, 1992) or photoelectric principle (McCormick and Stewart, 1966). Care should be taken with the power supply in short-circuit tools, since DC current and AC current of lower frequencies may affect pancreatic juice protein. The analog data from the flowmeter can be converted to digital and stored on the computer hard disk for further analysis (Naruse et al, 1992, Kiela et al, 1996). By means of these tools, several important data have been obtained concerning the kinetics of daily pancreatic secretion (circadian and ultradian rhythms, effects of meal), and the influence of regulatory peptides given in small, physiological-like doses (Itoh et al, 1980; Naruse et al, 1992, Guilloteau et al, 1997, Kiela et al, 1996).

A few servomechanism devices for the collection, measurement and reintroduction of pancreatic juice have been built in order to investigate pancreatic secretion under conditions as close to physiological as possible. These tools were usually equipped with a flowmeter and a device for infusion of pancreatic juice into the duodenum at the rate of juice secretion (Itoh et al, 1980; Juste et al, 1983; Le Dréan et al, 1997). All functions of the apparatus reported by Le Dréan et al (1997) collection of juice, sampling $8 \%$ of juice secretion, and infusion of the remainder back to the animal, were automated and controlled by computer. Thus, a daily profile of pancreatic secretion for a long period (limited only by computer memory capacity) can be obtained, giving the possibility to investigate physiological pancreatic rhythms and to perform developmental and nutrition studies. The movement of the animal in the cage, however, is limited by the length of the extension tubes, and the collecting system still has a non-negligible dead space (about $30 \mathrm{~mL}$ ). Nevertheless, we think that it is worthwhile to develop and perfect such systems. A small flowmeter attached to the animal's flank, connected directly to the implanted catheters, with a maximum $1 \mathrm{~mL}$ dead space, and a system for frequent sampling of pancreatic juice would constitute an optimal solution.

\section{SECRETION OF PANCREATIC JUICE IN ANIMALS PREPARED WITH DIFFERENT METHODS}

We are aware that the comparison of pancreatic juice parameters may be substantially influenced by many factors including diet, age, breed as well as by differences in the analytical methods used in the different laboratories (Wensing and Counotte, 1995). Therefore for illustrative purposes, we recommend the comparison studies: pouch vs Thomas method (Lee et al, 1986) and pouch vs Routley's method (Gabert et al, 1996, 1997) undertaken in the same laboratory.

Lee et al (1986) showed that the mean length of pancreatic secretory and duodenal motility cycles in dogs fitted with Herrera cannulas was significantly shorter than that of dogs fitted with Thomas cannulas. 
In the latter the motility cycles were of normal duration similar to non-cannulated dogs. Moreover, secretion of pancreatic juice (peak secretion and secretion per cycle) was higher in dogs fitted with Herrera cannulas than in dogs fitted with Thomas cannulas, while bicarbonate outputs showed the opposite results. No protein or enzyme data were compared in this study.

In the study of Gabert et al (1996), the pigs prepared with the duodenal pouch secreted substantially less bicarbonate, and demonstrated a much lower activity of trypsin, chymotrypsin, colipase and carboxyl ester hydrolase than the pigs with the catheter implanted in the duct. By contrast, the lipase activity and the total protein output were slightly increased with the pouch method. This suggests that enterotomy during pouch preparation cuts some essential neural pathways that regulate the amount of pancreatic secretion. This finding could be explained by a feed-back stimulation of enzymatic proteins followed by their inactivation by trypsin in the pouch. Moreover, in Routley's method, all the specimens showed much larger variations during each collection period, suggesting that this method is more sensitive to the physiological fluctuations of pancreatic secretions in the pig (Kiela et al, 1996). Electrophoretic separation of proteolytic enzymes showed that in the pancreatic juice collected using pouch method the proteolytic enzymes are near fully active or fully active (Gabert et al, 1997). Moreover, in the pouch method an inactivation or breakdown of some proteolytic enzymes has been evidenced in collected pancreatic juice. By contrast, in the Routley method the majority of enzymes was collected in an inactive form, and incubation of collected juice with enterokinase greatly increased the activity of enzymes.

Finally, some validation of Routley's method vs pancreatic tissue homogenates could be drawn from our studies in calves (Guilloteau et al, 1985, Le Dréan et al,
1997). Comparison of the results of interdigestive trypsin and chymotrypsin activities obtained in pancreas tissue homogenates and in pancreas juice showed parallel variations around weaning time as well as following changes of milk replacer formula.

\section{CONCLUSIONS}

To date there is no single, ideal chronic model of pancreatic juice collection. The methods reported so far present both advantages and serious limitations. Pouch methods do not collect pure inactive pancreatic juice and are surgically complicated. On the other hand, they do not need special care of the cannulas and seem to be adequate for longterm studies. Roultey catheters need systematic inspection and cleaning but are excellent to study the developmental aspects and neurohormonal regulations. The Thomas method eliminates the above mentioned drawbacks, but requires long postsurgical recovery and a rather strict immobilization of the test animal during collection. Therefore the best solution is to take into consideration all the advantages and disadvantages before adopting a single method for a particular study.

In conclusion, the various methods currently used are nevertheless capable of providing new and relevant information regarding the physiology and pathology of the exocrine pancreas. These methods are continually being modified; the materials for implantation and the conditions of animal maintainance are constantly improving. New tools for automated collection and registration of juice flow are under development. Dynamically developed non-invasive methods (eg, aspiration endoscopy) as well as in vitro techniques (perfusion studies of pancreas, studies on isolated pancreatic cells, etc) represent a significant supplement to chronic cannulation studies but cannot completely replace the current cannulation methods. Moreover, the physiological relevance 
of in vitro findings still needs to be validated in whole-animal studies on chronically cannulated animals.

\section{ACKNOWLEDGMENTS}

The help of Mrs D Fontaine in the language revision of the manuscript is gratefully acknowledged. This work was supported by the State Committee for Scientific Research (Poland), grant No 5 S310 01807.

\section{REFERENCES}

Aliev AA (1974) Opredelennye Metody Issledowanii Selskokhozjastvennych Zhivotnych. Nauka, Leningrad

Butler HC, Brinkman DC, Klavano PA (1960) Cannulation of the bovine pancreatic duct. Am J Vet Res 21, 205-211

Corring T, Aumaitre A, Durand G, Rerat A (1972) Permanent fistulation of the exocrine pancreas in the pig: Application to the response of pancreatic secretion to a meal. Ann Biol Anim Biochim Biophys 12, 109-124

Dragstedt LR, Montgomery ML, Ellis JC (1930) New type of pancreatic fistula. Proc Soc Exper Biol Med 28, 109-110

Gabert VM, Jensen MS, Jorgensen H, Engberg RM, Jensen SK (1996) Exocrine pancreatic secretions in growing pigs fed diets containing fish oil, rapeseed oil or coconut oil. J Nutr 126, 2076-2082

Gabert VM, Jensen MS, Westrom BR, Pierzynowski SG (1997) Electrophoretic separation of proteolytic enzymes in pancreatic juice collected with the pouch or catheter method. Int J Pancreatol (in press)

Grahame T (1943) Topographical Anatomy of the Dog. Ed O Charnockl Bradley, 4th ed. Oliver and Boyd Ltd, London, 45-47

Green GM, Miyasaka K (1983) Rat pancreatic response to intestinal infusion of intact and hydrolyzed protein. Am J Physiol G394-G398, 245

Guilloteau P, Corring T, Toullec R, Guilhermet R (1985) Enzyme potentialities of the abomasum and pancreas of the calf. II. Effects of weaning and feeding a liquid supplement to ruminant animals. Reprod Nutr Develop 25, 481-493

Guilloteau P, Le Huerou-Luron I, Chayvialle JA, Toullec R, Zabielski R, Blum JW (1997) Gut regulatory peptides in young cattle and sheep. $J$ Vet Med A $44,1-23$

Hee JH, Sauer WC, Berzins R, Ozimek L (1985) Permanent re-entrant diversion of porcine pancreatic secretion. Can J Anim Sci 65, 451-457
Herrera F, Kemp DR, Tsukamoto M et al (1968) A new cannula for the study of pancreatic function. $J$ Appl Physiol 25, 207-209

Hill KJ, Taylor RB (1957) Collection of pancreatic juice from the conscious sheep. $J$ Physiol 139, 26

Itoh Z, Honda R, Hiwatashi K (1980) Biphasic secretory response of exocrine pancreas to feeding. Am $J$ Physial G332-G337, 238

Juste C, Corring T, Le Coz Y (1983) Bile restitution procedures for studying bile secretion in fistulated pigs. Lab Anim Sci 33, 199-202

Kato S, Usami M, Ushijima J (1984) The effect of feeding on pancreatic exocrine secretion in sheep. Jpn J Zootechn Sci 55, 973-977

Kiela P, Zabielski R, Podgurniak P, Midura M, Barej W, Gregory PC, Pierzynowski SG (1996) Cholecystokinin-8 and Vasoactive Intestinal Polypeptide stimulate exocrine pancreatic secretion via duodenal mediated mechanisms in the conscious pig. Exp Physiol 81, 375-384

Konturek SJ, Dubiel J, Gabrys B (1970) New methods of forming the chronic pancreatic fistula in cats. Acta Physiol Pol 21, 483-490

Le Dréan G, Le Huerou-Luron I, Chayvialle JA, Philozue-Romé V, Gestin M, Bernard C, Toullec R, Guilloteau $P$ (1997) Kinetics of pancreatic exocrine secretion and plasma gut regulatory peptide release in response to feeding in preruminant and ruminant calves. Comp. Biochem. Physiol. A (in press)

Lee KY, Shiratori K, Chen YF, Chang T-M, Chey WY (1986) A hormonal mechanism for the interdigestive pancreatic secretion in dogs. Am J Physiol G759-G764, 251

Le Meuth V, Philouze-Romé V, Le Huerou-Luron I, Formal M, Vaysse N, Gespach C, Guilloteau P, Fourmy D (1993). Differential expression of Aand B-subtypes of cholecystokinin/gastrin receptors in the developing calf pancreas. Endocrinology 133, 1182-1191

Magee DF (1961) An investigation into the external secretion of the pancreas in sheep. J Physiol 158 , 132-143

Magee DF (1991) Is there a duodenal-pancreas negative feed-back? Int J Pancreatol 8, 367-377

Magee DF, Naruse S (1983) Neural control of periodic secretion of the pancreas and the stomach in fasting dogs. J Physiol 344, 153-160

Markowitz J (1954) Experimental Surgery, 3rd ed. The Williams \& Wilkins Company, Baltimore, MA, USA

McCormick RJ, Stewart WE (1966) Pancreatic secretion in the bovine calf. $J$ Dairy Sci 50, 568-571

Naranjo JA, Valverde A, Martinez de Victoria E, Manas M, Moreno M (1986) Surgical preparation for the study of pancreatic exocrine secretion in the conscious preruminant goat. Lab Anim 20, 231233

Naruse S, Suzuki T, Ozaki T (1992) The effect of pituitary adenylate cyclase activating polypeptide 
(PACAP) on exocrine pancreatic secretion in dogs. Pancreas 7, 543-547

Nickel R, Schummer A, Seiferle E, Sack WO (1979) The Viscera of the Domestic Mammals. Verlag Paul Parey, Berlin, Hamburg, Germany

Onaga T, Zabielski R, Mineo H, Kato S (1993) The temporal coordination of interdigestive pancreatic exocrine secretion and intestinal migrating myoelectric complex in rats. $X X X I /$ Congress Int Union Physiological Sciences, Glasgow, Great Britain, 1-6 Aug, 1993, 95.1/P, 83

Ormai S, Sasvari M, Endroczi E (1986) A new technique for chronic pancreatic cannulation in rats. Scand J Gastroenterol 21, 509-512

Owyang C (1996) Physiological mechanisms of cholecystokinin action on pancreatic secretion. Am J Physiol 271, G1-G7

Pierzynowski SG (1983) A method of collecting pancreatic juice and bile in conscious sheep. Ann Warsaw Agricult Univ-SGGW-AR, Vet Med 11, 65-67

Pierzynowski SG, Barej W, Mikolajczyk M, Zabielski R (1988a) The influence of light fermented carbohydrates on the exocrine pancreatic secretion in cows. J Anim Physiol Anim Nutr 60, 234-238

Pierzynowski SG, Weström BR, Karlsson BW, Svendsen J, Nilsson B (1988b) Pancreatic cannulation of young pigs for long-term study of exocrine pancreatic function. Can J Anim Sci 68, 953-959

Pierzynowski SG, Weström BR, Svendsen J, Karlsson BW (1990) Development of exocrine pancreas function in chronically cannulated pigs during 1-13 weeks of postnatal life. I Pediatr Gastroenterol Nutr 10, 206-212

Pierzynowski SG, Sharma P, Sobczyk J, Garwacki S, Barej W (1992) Influence of feeding regimen and postnatal developmental stages on antibacterial activity of the pancreatic juice. Int $J$ Pancreatol $12,121-125$

Preshaw RM, Grossman MI (1965) Stimulation of pancreatic secretion by extracts of the pyloric gland area of the stomach. Gastroenterology 48, 36-44

Routley EF, Mann FC, Bollman JL, Grindlay JH (1952) Effects of vagotomy on pancreatic secretion in dogs with chronic pancreatic fistula. Surg Gynec Obstet 95, 529-536

Scott VB, Collington UJ, Bugel HJ, Johnson GC (1941) The relation of external pancreatic secretion to variations in blood sugar. Am J Physiol 134, 208-218

Stening GF (1969) A modification of a chronic pancreatic fistula in the dog. Brit J Surg 56, 782-787
St-Jean G, Harmon DL, Peters JP, Ames NK (1992) Collection of pancreatic exocrine secretions by formation of a duodenal pouch in cattle. Am J Vet Res $53,2377-2380$

Ternouth JH, Buttle HL (1973) Concurrent studies of the flow of digesta in the duodenum and of exocrine pancreatic secretion of calves. The collection of the exocrine pancreatic secretion from a duodenal cannula. Br J Nutr 29, 387-397

Teyssen S, Niebergall-Roth E (1996) Pancreatic studies in intact dogs. In: Methodology in Pancreatic Physiology, workshop materials. First Combined Meeting of the European Pancreatic Club and the International Association of Pancreatology, (Mannheim, Germany) 11-18

Thomas JE (1941) An improved cannula for gastric and duodenal fistulas. Proc Soc Exp Biol Med 46, 260-261

Thomas JE, Crider JO (1946) The secretion of pancreatic juice in the presence of atropine or hyoscyamine in chronic fistula dogs. $J$ Pharmac Exp Ther 87, 81-89

Vodovar N, Flanzy J, Francois AC (1964). Intestin grêle du porc. I. Dimensions en fonction de l'âge et du poids ; étude de la jonction du canal cholédoque et du canal pancréatique à celui-ci. Ann Biol Anim Biochim Biophys 4, 27-34

Wass WM (1965) The ducts systems of the bovine and porcine pancreas. Am J Vet Res 26, 267-272

Waynforth HB (1980) Experimental and Surgical Technique in the Rat. Academic Press Inc, London, UK

Wensing T, Counotte GHM (1995) The impact of the reproducibility of clinical-, biochemical- and hematological variables in diagnosing production diseases. IXth Int Conf Production Diseases in Farm Animals, 1995, Free University of Berlin, Germany 61

Winnicki T (1994) Nowa metoda długotrwałej kaniulacji trzustki u świń. Medycyna Wet 50, 37-40

Zabielski R, Kato S, Pierzynowski SG, Mineo H, Podgurniak P, Barej W (1992) Effect of intraduodenal $\mathrm{HCl}$ and soybean extract on pancreatic juice secretion during atropinization and cold vagal blockade in calves. Exp Physiol 77, 807-817

Zabielski R, Onaga T, Mineo H, Kato S (1993) Periodic fluctuations in pancreatic secretion and duodenal motility investigated in neonatal calves. Exp Physiol 78, 675-684

Żebrowska T, Low AG, Żebrowska H (1983) Studies on gastric digestion of protein and carbohydrate, gastric secretion and exocrine pancreatic secretion in the growing pig. Br $J$ Nutr 49, 401-410 